\title{
The Meanings Ascribed to Happiness, Life Satisfaction and Flourishing
}

\author{
Margarita Bakracheva \\ Sofia University, Sofia, Bulgaria \\ Email:m.bakracheva@abv.bg
}

How to cite this paper: Bakracheva, M. (2020). The Meanings Ascribed to Happiness, Life Satisfaction and Flourishing. Psychology, 11, 87-104.

https://doi.org/10.4236/psych.2020.111007

Received: November 11, 2019

Accepted: January 5, 2020

Published: January 8, 2020

Copyright $\odot 2020$ by author(s) and Scientific Research Publishing Inc. This work is licensed under the Creative Commons Attribution International License (CC BY 4.0).

http://creativecommons.org/licenses/by/4.0/

(c) (i) Open Access

\begin{abstract}
This study aims at describing what happiness, life satisfaction, and flourishing mean for the respondents and did the previously generated associations influence the self-reported levels of well-being. The design of the study is cross-sectional, qualitative and quantitative. The sample comprises 351 volunteers aged 20 - 55, divided into two groups. Both groups have been administered happiness and life satisfaction scales and PERMA profiler. One of the groups simply replied to the self-reported scales, while the volunteers from the second group have been asked to generate free associations of words/ expressions they relate to the happiness, life satisfaction, and flourishing prior to reply to the self-report scales. The results reveal that the free generated associations for happiness, life satisfaction, and flourishing, have common, however different meaning. Happiness turns out to be linked mostly with intrinsic predictors, e.g. love, balance and harmony, whereas life satisfaction comprises extrinsic (self-realization, success) and intrinsic factors (close people, positive emotions). Flourishing is most of all explained by similar concepts (happiness, life satisfaction) and also relates both to extrinsic and intrinsic domains (career, satisfaction; love, and joy). Previously generated associations have no effect on the reported experienced happiness and life satisfaction and have partial effect on the flourishing scales. The positive emotions and relations are not influenced; however self-reflection is related to the cognitive variables. When respondents have first thought about what flourishing means for them, they give lower scores for accomplishment, engagement and life meaning. This suggests that well-being is related to different intrinsic and extrinsic predictors that follow different pathways and this is one of the keys for promotion of flourishing.
\end{abstract}

\section{Keywords}

Happiness, Life Satisfaction, Well-Being, Flourishing, PERMA Profiler 


\section{Introduction}

During the preceding two decades the interest in positive psychology remains stable due to the implications of optimal functioning not only at individual, but at community level as well. I am interested in the measures of well-being especially because of the different picture when the survey is of national scale and when the comparison is cross-cultural. Differences among countries are predicted mostly by GDP, social equality, political freedom, individualism and democracy, which are accounted as having key importance (Veenhoven, 1992; Diener \& Suh, 1998; Inglehart \& Klingemann, 2000), supplemented by tacit features, related to the national psychology.

Bulgarians are usually described as the least happy and satisfied with life nation (Diener \& Oishi, 2000; Inglehart \& Klingemann, 2000; Veenhoven, 2000). In latest research on well-being and flourishing, experienced as feeling good and functioning effectively, Bulgarians score lower compared to more of the Eastern European countries, especially in relation to emotional stability, positive emotion, resilience (Huppert \& So, 2013). European Social Surveys outline the overall index of well-being for each country-in general, Denmark, Switzerland and Norway have the highest levels of overall well-being, while Ukraine, Bulgaria and Hungary, have the lowest. In ESS6 Bulgarians are also reported to be the least satisfied with life and the least happy of 29 countries across Europe. In the World Happiness Report (2019), comprising 156 countries, Bulgaria ranks $97^{\text {th }}$ in the world between Cameroon and Ghana in terms of happiness, being unhappier than almost all Balkan countries. Romanians, who are usually compared to Bulgarians in the EU, are twice as happy as Bulgarians. These are just a few of the examples of this repeatedly reported trend. Even comparison of student samples, comprising 48 countries, rank Bulgarian students at 37th position for life satisfaction and at 47th for happiness (unpublished IVS, 2010). In the latest Eurostat data, Bulgaria takes last position in terms of feeling happy during the preceding 4 weeks. To some extent, this difference can be explained by the very low score on Hofstede's dimension Indulgence-restraining cultures usually are cynic and pessimistic and do not tend to express their emotions.

[https://www.hofstede-insights.com/product/compare-countries/]. This, however, does not mean that no positive emotions are experienced. Furthermore, the meanings ascribed to happiness and life satisfaction are related to different domains. When it comes to assessment of quality of life, environment and real living conditions, the scores are inevitably low because people take into account the environmental factors. On the contrary, happiness and positive emotions have nothing in common with the environmental restrictions. Therefore, I am interested in studying and outlining the predictors of WB at national level and what do Bulgarians associate with happiness, subjective well-being and flourishing on one hand, and have the results for flourishing through the PERMA profiler, which has not been administered in Bulgaria, on the other. In my previous studies, I have found that people in Bulgaria are happy, nevertheless dissatisfied with 
their life (Bakracheva, 2009; Bakalova et al., 2015). In respect to flourishing, I have administered Diener's flourishing scale (Diener et al., 2009) and confirmed that also, despite the cross-cultural comparisons, in national scale Bulgarians are flourishing (Bakracheva, 2019).

\section{Theoretical Background-Definition and Components of Happiness}

There is no single definition of well-being and it is generally regarded as the universal strive of people for happy and satisfying life. Nowadays, the focus has shifted on the community prosperity. The studies of well-being exceed 2000 and usually they are targeted at different variables in emotional and cognitive domains, measured with various instruments (Veenhoven, 2017). Happiness is often used interchangeably with well-being and quality of life as indicator of individual and social welfare. It is suggested to comprise both affects and thoughts (Veenhoven, 1984, 2010). The hedonic component refers to pleasant experiences, feelings, emotions, states, and moods, measured in different time intervals-week, year, and over a lifetime. The second component is the contentment or the degree, to which an individual subjectively perceives that his/her aspirations are attained or satisfied (Veenhoven, 2009). The distinction between affective and cognitive aspects of happiness is along with their conceptualization as components of the overall happiness. Evidence indicates that subjective wellbeing, life satisfaction, optimism, happiness, and other positive constructs are associated with numerous desirable outcomes, among which success, positive relations, and better physical health (Lyubomirsky et al., 2005; Huppert, 2009; Diener \& Chan, 2011).

Hedonic well-being is the subjective or emotional well-being, comprising the components happiness, life-satisfaction and positive-negative affect balance (Diener, 1984). Concerning the emotional component of well-being the sustainable happiness model postulates that personal chronic happiness level can be increased and sustained afterwards. The eudaimonic well-being is the strive after self-actualization and revealing one's full potential, conceptualized in the classical theory of self-actualization (Maslow, 1954) as a natural and dynamic life-long process of growth with full concentration and absorption. Eudaimonic well-being is related to satisfaction of the basic psychological needs that are considered innate and which satisfaction is said to represent a universally essential experience for wellbeing (Ryan et al., 2008). The common position is that both hedonic and eudaimonic activities should be pursued for the most optimal and diverse well-being (Huta \& Ryan, 2010). Reiss \& Havercamp (2005) suggest that the age of 36 is the reasonable cut-point of the specific age for the attainment of self-actualization. The lifespan approach also considers middle age the period for effective self-reflection, re-assessment, and finding the balance between the intrinsic motivation and social norms (Huyck, 1993; Shek, 1996; Lachman, 2004).

Based on the large body of research it can be summarized that one of the ap- 
proaches to measuring well-being is focused on emotions (hedonic well-being), while the other is focused on its eudaimonic elements. The components or predictors of well-being are also various, depending on the theoretical framework. Some researchers describe the opposite of the negative emotions and states. An example for this is the 10 opposites of depression and anxiety, suggested as components of well-being and flourishing: competence, emotional stability, engagement, meaning, optimism, positive emotion, positive relationships, resilience, self-esteem, vitality (Huppert \& So, 2013). Other models describe the pure components, promoting the well-being, e.g. the hedonic, prudential (fully engaged), eudaimonic, and chaironic (feeling blessed) types of happiness and their subjective expression (Wong, 2011). The general conclusion is that the lack of negative states, e.g. anxiety and depression and negative affect, does not always mean positive emotions and life meaning, positive affect, happiness, social connection, trust, and wellness. There are numerous indicators and multidimensional predictors and components necessary to describe the complexity of optimal functioning as a whole (Baltes \& Baltes, 1990; Forgeard et al., 2011; Friedman \& Kern, 2014).

Flourishing can be summarized both as an attitude and as a dynamic optimal state of psychosocial functioning in different psychosocial domains. A key point is the balance of intrinsic and extrinsic components-both subjective experience, but also the positive feedback from the community and environment. In Seligman's model of flourishing (Seligman, 2011, 2012) it is described by the PERMA abbreviation: positive emotions, engagement, relationships, meaning, and accomplishment. The role of positive emotions is well supported across a range of life outcomes (Lyubomirsky et al., 2005; Howell et al., 2007; Huppert, 2009). Engagement as full absorption, and focus is best presented in the flow theory (Csikszentmihalyi, 1990). Relationships or feeling loved, supported, and valued by others has also significant impact on well-being (Seligman, 2012). Meaning is related to direction in life, perceiving life as valuable and worthwhile (Steger, 2012). Accomplishment represents the devotion and pursue of goals, mastery, and efficacy in completion of goals and tasks, imposed by the universal need of achievement (Seligman, 2012).

\section{Present Study}

In this study are included both the hedonic and eudemonic components of well-being-the measures of happiness, life satisfaction and flourishing-were administered to respondents, divided into two groups. Before to respond to the scales one of the group was asked to generate free associations about the first words/expressions/images associated with happiness, life satisfaction and flourishing. The expectations were three-folded: 1) That the three measures of wellbeing will generate different key categories of associations describing what people perceive subjectively in respect to happiness, life satisfaction and flourishing; 2) That there would be a difference in the results of the two groups of respon- 
dents-those who have given free associations and those who have simply replied to the self-reporting scales, because the first group of volunteers would first focus on the essence of the important life domains; 3) That the levels of wellbeing components would be high based on our previous results and the fact that well-being has both intrinsic and extrinsic predictors.

\subsection{Participants}

Participants were recruited from three Bulgarian universities (Sofia University St. Kliment Ohridski, Military Academy G. S. Rakovski and Plovdiv University St. Paisii Hilendarski. These were students in master programmes, first master or part of life-long development (second master degree), which is rather popular in Bulgaria, via convenience sampling. I asked these preliminary recruited participants to include their family members/relatives in view to recruit people who are only working and who are unemployed. I tried also to recruit people of different family status, occupation, age and sex with view to divide the sample according to these previously known variables into two groups. The sample comprises 351 volunteers aged $20-55$, not completely equally distributed. The general group comprises: gender (sex) $-23 \%$ men, $77 \%$ women; occupation: working $46 \%$, studying $10 \%$, unemployed $6 \%$, working and studying $38 \%$; family status: $44 \%$ married; $19 \%$ living in cohabitation; $16 \%$ single, living with others $21 \%$; incomes: below the average $10 \%$, average $66 \%$, above the average $24 \%$. Age: below 30 years $25 \%$, 30 - 40 years aged $30 \%, 40$ - 50 years aged $32 \%$; above 50 years $13 \%$. The sample was divided based on sex, occupation, age and marital status (subjective assessment of the income had not been known previously; it was included in the instrument only) and $62 \%$ of the participants were first asked to generate free associations for happiness, life satisfaction and flourishing on blank sheets. All participants were administered happiness and life satisfaction scales and PERMA profiler. The percent distribution of the sample divided in two groups is illustrated below (Figure 1).

\subsection{Measures Used}

Subjective happiness scale (General Happiness Scale) (Lyubomirsky \& Lepper, 1999). A 4-item scale designed to measure subjective happiness. The first two items refer to subjective assessment of overall happiness and in comparison to others with 5-point Likert scale and responses from "not very happy" to "very happy" and "less" to "more" happy. The rest two items measure the attitudes towards happiness-that some people are generally (un)happy with 5-point Likert scale from "not at all" to "a great deal". One component explaining $66.34 \%$ of the variance is extracted.

Satisfaction with life scale (Diener et al., 1985), Bulgarian translation (https://eddiener.com/scales/7). A 5-item scale designed to measure global cognitive judgments of one's life satisfaction. Participants indicate how much they agree or disagree with each of the 5 items, using a 5 -point scale that ranges from 


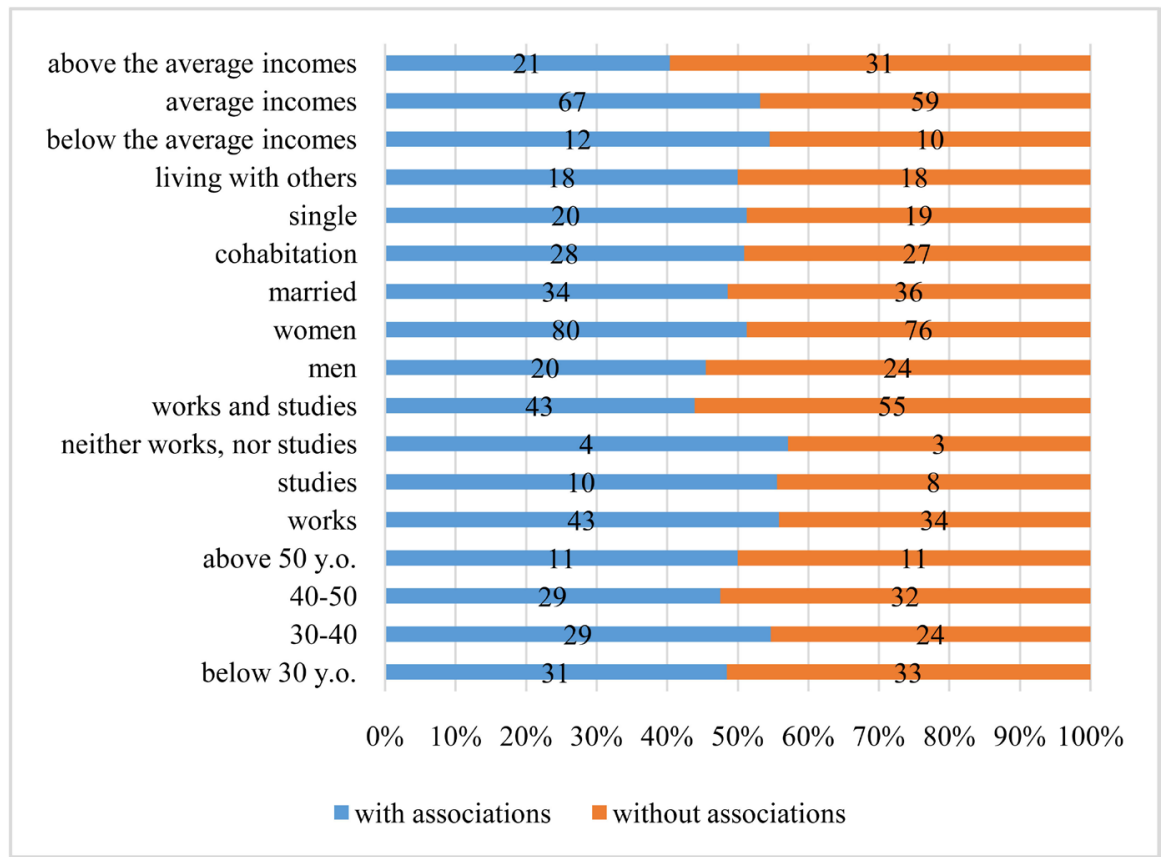

Figure 1. Distribution of the two groups of the sample.

7 "strongly agree" to 1 "strongly disagree". One component is extracted explaining $61,452 \%$ of the variance.

PERMA Profiler (Butler \& Kern, 2016). Perma profiler comprises 23 items, 16 forming the general profile ( 3 items for each of the 5 domains and overall assessment of happiness; overall measure of loneliness, negative emotions and health ( 3 for the last two domains). For Positive emotion, the PERMA Profiler measures general tendencies toward feeling contentment and joy. For Negative emotion, the Profiler measures tendencies toward feeling, sad, anxious, and angry. Engagement refers to being absorbed, interested, and involved in an activity or the environment, represented in the state called "flow". Relationships refer to feeling loved, supported, and valued by others. Meaning refers to having a sense of purpose in life, a direction where life is going, feeling that life is valuable and worth living, having a personally meaningful goal. Accomplishment can be objective, marked by honours and awards received, but also includes feelings of mastery and achievement. In addition to PERMA model physical health is included as an important part of well-being. Respondents rate each item on a 5-point scale: 1: "does not describe me"/"completely describes me"; "never- always"; "little-much". 5 components are extracted for PERMA, explaining $38.48 \%, 8.26 \%, 6.39 \%, 5.50 \%, 4.62 \%$ and cumulatively $63.27 \%$ of the variance.

Free associations have been subject to content-analysis and some of the techniques of the figurative language identification procedure (developed by Stoitsova \& Polio, 2004). After the word counting the unique words and expressions, the remaining ones have been grouped into semantic fields by three independent experts. 


\subsection{Variables and Procedure}

Variables accounted here are happiness, life satisfaction, and the five components of flourishing according to the PERMA model-positive emotions, engagement, relationships, meaning, and accomplishment. A cross-sectoral predictive research design was carried out. The study is based on primary data. Data were collected from voluntary and anonymous participation. The study is designed with two groups of respondents-one group administered only the selfreport scales for happiness, life satisfaction and flourishing and the other group that prior to self-report experienced well-being has been asked to give free associations what are the first words/expressions occurred for happiness, life satisfaction and flourishing. Data were collected during the summer $\left(15^{\text {th }} \mathrm{June}-20^{\text {th }}\right.$ July 2019). The received 351 complete answers were from distributed 400 paper-and-pencil forms. Data were analysed by reliability analyses, descriptive statistics and ANOVA (IBM SPSS Statistics 25). Assessment and categorization of the free associations followed quantitative and summative approach, i.e. counting the frequency of words and their underlying meaning.

\section{Results}

In this section will be presented first the general statistics for the scales measuring happiness, life satisfaction and flourishing. Next the groups of the free associations for happiness, life satisfaction and flourishing and description of the effect of associations on subjective responses for experienced well-being and finally the comparative illustration of the results for PERMA profiler of this sample with some of the published data for PERMA profiler.

Table 1 outlines the general statistics. For all variables the minimum scores are above the objective minimum 1 on the 5-position scale and all the means are

Table 1. Descriptive statistics.

\begin{tabular}{|c|c|c|c|c|c|c|}
\hline Variables & $\mathrm{N}$ & Minimum & Maximum & Mean & Std. Deviation & $\begin{array}{c}\text { Cronbach's } \\
\text { Alpha }\end{array}$ \\
\hline Happiness & 351 & 1.75 & 5.00 & 3.96 & 0.767 & 0.821 \\
\hline Life satisfaction & 351 & 1.60 & 5.00 & 3.75 & 0.729 & 0.832 \\
\hline $\mathrm{Fl}^{*}$-positive emotions & 351 & 2.33 & 5.00 & 3.65 & 0.405 & 0.862 \\
\hline Fl-engagement & 351 & 2.33 & 4.67 & 3.48 & 0.431 & 0.675 \\
\hline Fl-relations & 351 & 2.00 & 5.00 & 3.98 & 0.575 & 0.612 \\
\hline Fl-meaning & 351 & 2.00 & 5.00 & 4.01 & 0.694 & 0.637 \\
\hline Fl-accomplishment & 351 & 2.33 & 5.00 & 3.49 & 0.476 & 0.735 \\
\hline PERMA & 351 & 2.69 & 4.63 & 3.73 & 0.381 & 0.718 \\
\hline Fl-happiness & 351 & 2.00 & 5.00 & 3.93 & 0.884 & \\
\hline Fl-negative emotions & 351 & 2.00 & 5.00 & 4.06 & 0.658 & 0.673 \\
\hline Fl-health & 351 & 2.33 & 4.67 & 3.45 & 0.392 & 0.732 \\
\hline
\end{tabular}

${ }^{\star} \mathrm{Fl}$-flourishing. 
above the average. The reliability of the scales is acceptable. Meaning and negative emotions have highest scores. In summary, for this sample respondents score above the middle point for happiness, life satisfaction and flourishing measures regardless the experienced intensive negative emotions.

Post hoc tests for effect of sex, age, gender, occupation, family status and income reveal that all the variables in total explain a small percent of the variance ( $\mathrm{R}$ square, $113 ; \mathrm{F}=5.651 ; p<0.000$ with individual effect solely of income ( $\beta$, $266 ; \mathrm{t}=3676 ; p<0.000)$. The single effects of demographic variables are slight and partial. Sex and age have no significant effects. Occupation has effect on happiness $(\mathrm{F}=2736 ; p<0.031)$ and PERMA variable accomplishment $(\mathrm{F}=3431$; $p<0.011$ ). Those who work and study (mean difference, 67,917; $p<0.036$ ) or only work (mean difference, 84,722; $p<0.009$ ) are happier compared to those who neither work, nor study. Family status has effect only on happiness $(\mathrm{F}=$ 5227; $p<0.002)$. Married report to be happier compared to those living in cohabitation (mean difference, 43,877; $p<0.008$ ) and those living with others (mean difference, 54,044; $p<0.001$ ). Subjective assessment of personal income has effect on happiness ( $\mathrm{F}=12,161 ; p<0.000)$; and life satisfaction $(\mathrm{F}=6626 ; p<$ 0.002) and for PERMA on positive emotions (3891; $p<0.023$ ). People having income above the average, are happier compared to those having income below the average income (mean difference $1,12,821 ; p<0.000$ ) and having average income (mean difference, 33,545; $p<.014$ ) and more satisfied compared to those with income below the average (mean difference, 50306; $p<0.016$ ) and average (mean difference, 29,694; $p<0.026$ ). Surprisingly, people having income below the average, experience more positive emotions compared to the group having incomers above the average (mean difference, 48,889; $p<0.009$ ).

In Table 2, the free associations of respondents generated for happiness are described. The total generated associations for happiness are 555.53 associations are not included here because they cannot be grouped without further information (e.g. mom).

The associations are grouped into 16 categories. The two categories, which have been grouped semantically by the experts, are in bold in the table-associations, related to states of mind and souls and associations, explaining happiness with similar words. All the remaining categories reflect the direct words generated by the respondents. The first ranking category to which the respondents relate happiness, most of all is love. Second come the associations of happiness with states of mind and soul (peace, harmony, and balance). The category health ranks third, followed by joy and smile. Next come associations describing happiness with similar words, positive relations and sharedness, and freedom. Sea and sun have special place. Family and children come along with nature, air and breathing, completeness and meaning. Travelling, money, music and quietness rank almost equally. What makes respondents happy, are intrinsic stimuli. These are primarily love-feeling loved and giving love to others, in all its forms. People experience happiness also as internal balance and joy. Most of the words 
Table 2. Associations generated for happiness

\begin{tabular}{cc}
\hline Associations & Frequency \\
love & 72 \\
states (of soul, mind) & \\
inner peace, harmony, balance, piece of mind & 68 \\
health & 50 \\
joy, smile, laughter & 47 \\
associations with similar words & \\
success, recognition, satisfaction, realization, well-being, & 46 \\
bliss, emotional state, ecstasy, flourishing & \\
freedom, independence, flight & 45 \\
soul mate, affection, sharedness, warmth, friends & 40 \\
sea, sun & 32 \\
family & 29 \\
air, breathing, nature & 27 \\
completeness, meaning & 25 \\
children & 21 \\
travelling & 15 \\
money & 14 \\
music & 12 \\
quietness & 12 \\
\hline
\end{tabular}

associated with happiness, relate to intrinsic stimuli and experiences.

The portrait of the happy person is the one who is loved, lives in harmony and balance, who is healthy and full of joy. This ensures sense of well-being and bliss, experienced freedom and independence. Happy person perceives support, empathy and warmth in relations with friends and family. Sea, sun, travelling and probably money namely for this, complete the requisites for happiness.

Generated associations for life satisfaction are 532 (Table 3).

The associations for life satisfaction are grouped also into 16 categories. The two categories, which have been grouped semantically by the experts, are in bold in the table-the associations, explaining life satisfaction with similar words and the group of "oughts and should", which is specific solely for the life satisfaction experience. All the remaining categories reflect the direct words generated by the respondents.

With regard to life satisfaction the leading category in associations is self-realization, recognition and success, followed by inner states of balance, harmony, love, health. Financial stability is equally important with positive emotions and travelling, followed by sense of completion and mission. Only for satisfaction with life appears the category of internalized expectations-the oughts and should. Children, security, activities in leisure time and sense of hope are also important. Life satisfaction is experienced in relation to the objective and subjective goals. Realization of goals and personal success are measured by the respondents both in comparison to objective and subjective criteria. Life satisfaction is 
Table 3. Associations generated for Life satisfaction.

\begin{tabular}{cc}
\hline Associations & Frequency \\
\hline realized goals, dreams, professional and personal realization, recognition, success & 68 \\
calmness, balance, harmony, inner peace & 54 \\
work, occupation, career (satisfaction, dreamed) & 50 \\
friends, close people, sharedness, positive relations & 50 \\
associations with similar words & \\
happiness, welfare, well-being & 45 \\
love & 37 \\
health & 34 \\
joy, smile & 30 \\
travelling & 30 \\
money, financial stability, comfort, quality of life & 30 \\
meaning, mission, cause, completeness & 28 \\
oughts and shoulds & 18 \\
to know who you are, to help others, etc. & 17 \\
children & 12 \\
security, stability & 12 \\
leisure time & \\
hope, gratefulness & 12 \\
\hline
\end{tabular}

predicted by self-assessment in respect to external factors.

The portrait of the satisfied with life is the one person, who has attained personal goals and has sense of success ensuring her/him balance and harmony. The satisfied person has positions in the community, good relations with others, feels love and is healthy. (S) he is financially stable, experiences positive emotions, travels and has meaningful life. $(S)$ he is concerned for the environment and the expectations of others, however values leisure time and inner hope.

Table 4 summarises the 567 associations for Flourishing. 38 of the associations are excluded as they cannot be assigned properly without further explanations.

For flourishing, the categories of associations are more compared to happiness and life satisfaction-18. The only category, grouped semantically by the experts, in bold in the table, comprises associations, explaining the experience of flourishing as happiness and life satisfaction. All the remaining categories reflect the direct words generated by the respondents.

Flourishing refers mainly to self-reflection and associations with similar words for well-being and optimal functioning. Professional satisfaction, love, family, self-realization, health, children, positive emotions and friends come next. Equal importance is given to harmony, balance, hope, sharedness, travelling, security, respect, freedom, completeness and money. Here I have to mention the greatest number of unique words. Flourishing is explained most of all by associations of happiness and life satisfaction. Probably because of this, it is related both to intrinsic and extrinsic stimuli and predictors. 
The portrait of the flourishing person is a person who is mindful and self-reflective, satisfied with her/his career, giving and receiving love, having a good family, feeling self-realized and healthy, satisfied with children, experiencing positive emotions, having good friendships, maintaining inner peace and harmony, full of hope, feeling safe and secure, being respected, feeling free and complete and financially stable.

The leading categories and differences in associations, generated for happiness, life satisfaction, and flourishing can be summarized, as follows (Table 5):

Table 4. Associations generated for flourishing.

\begin{tabular}{|c|c|}
\hline Associations & Frequency \\
\hline \multicolumn{2}{|l|}{ associations with similar words } \\
\hline (happiness, life satisfaction) & 77 \\
\hline Work, career and professional satisfaction & 69 \\
\hline Love & 59 \\
\hline Family & 55 \\
\hline Self-development, self-realization, attained goals, success & 55 \\
\hline Health & 54 \\
\hline Children & 32 \\
\hline Positive emotions and joy & 29 \\
\hline Friends & 18 \\
\hline Inner peace and harmony, balance, inner satisfaction, calmness & 16 \\
\hline Hope & 14 \\
\hline Sharing, empathy, and belongingness & 14 \\
\hline Travelling & 14 \\
\hline Feeling safe and secure & 13 \\
\hline Respect & 12 \\
\hline Freedom & 12 \\
\hline Completeness & 12 \\
\hline Money & 12 \\
\hline
\end{tabular}

Table 5. Leading categories for happiness, life satisfaction and flourishing.

\begin{tabular}{|c|c|c|}
\hline $\begin{array}{l}\text { Happiness is predicted } \\
\text { most of all by intrinsic } \\
\text { states }\end{array}$ & $\begin{array}{l}\text { Life satisfaction is determined most } \\
\text { of all by extrinsic and intrinsic } \\
\text { factors }\end{array}$ & $\begin{array}{l}\text { Flourishing relates most of } \\
\text { all to self-reflection, extrinsic } \\
\text { and intrinsic factors }\end{array}$ \\
\hline $\begin{array}{l}\text { love, peace, harmony, } \\
\text { balance, health, joy, smile, } \\
\text { laughter, success, } \\
\text { recognition, satisfaction, } \\
\text { realization, well-being, bliss, } \\
\text { emotional state, ecstasy, } \\
\text { flourishing }\end{array}$ & $\begin{array}{l}\text { realized goals, dreams, professional } \\
\text { and personal realization, recognition, } \\
\text { success, career, calmness, balance, } \\
\text { harmony, inner peace, friends, close } \\
\text { people, sharedness, positive relations, } \\
\text { happiness, welfare, well-being }\end{array}$ & $\begin{array}{l}\text { similar concepts related to } \\
\text { well-being (happiness, life } \\
\text { satisfaction), work, career and } \\
\text { professional satisfaction, } \\
\text { self-development, } \\
\text { self-realization, attained goals, } \\
\text { success, love, family }\end{array}$ \\
\hline
\end{tabular}


The difference outlined is that happiness turns out to be mostly related to intrinsic states and experiences, whereas life satisfaction is dominated by extrinsic, followed by intrinsic predictors in associations. In its turn, flourishing is most of all related to mindfulness and self-reflection, and is linked with extrinsic and intrinsic stimuli. Life satisfaction and flourishing are closer in contents compared to happiness. Happiness has dominantly intrinsic sources and probably this is the reason to have higher mean score and be higher in quantitative scales than the assessment of environmental factors. The mean of happiness is higher compared to life satisfaction and PERMA profile. Life satisfaction, being cognitive component, has no significant difference in the means in comparison to PERMA (Table 6). The different sources of pursuing and the meaning ascribed to happiness, life satisfaction, and flourishing, can explain to some degree the difference in the self-reported scores.

Table 7 describes the significant effects of the generated free associations on the responses to well-being scales.

In any case, with or without significant effect, generation of associations results in lower self-reported well-being.

Associations have no effect on happiness, positive emotions and relations, e.g. on the emotional well-being. Furthermore, the effect on cognitive component is also partial. Associations do not influence the assessment of subjective well-being. Self-reflection seems to have made respondents report lower scores for meaning, accomplishment and engagement and thus indirectly has effect on the overall PERMA score.

In support of the result on the meaning ascribed to flourishing, the effect of associations on its components supports the role of self-reflection. People are influenced by the framework of their perceptions and experienced environmental framework, i.e. the external stimuli and predictors.

Finally, to further illustrate this, a partial comparison was made based on some of the published data for flourishing and PERMA Profiler (Butler \& Kern, 2016). I have taken the overall results and the results for Russia for comparison (Table 8). Having only the means, the significant differences are measured using the standard formula applied in social sciences statistics:

Table 6. Paired samples statistics.

\begin{tabular}{|c|c|c|c|c|c|c|c|}
\hline & $\mathrm{N}$ & Mean & Std. Deviation & $\mathrm{t}$ & Sig. (2-tailed) & Correlation & Sig. \\
\hline Happiness & 351 & 3.9620 & 0.74697 & \multirow{2}{*}{4.842} & \multirow{2}{*}{0.000} & \multirow{2}{*}{0.687} & \multirow{2}{*}{0.000} \\
\hline Life satisfaction & 351 & 3.7533 & 0.72954 & & & & \\
\hline Happiness & 351 & 3.9620 & 0.74697 & \multirow{2}{*}{5.190} & \multirow{2}{*}{0.000} & \multirow{2}{*}{0.583} & \multirow{2}{*}{0.000} \\
\hline PERMA & 351 & 3.7287 & 0.37901 & & & & \\
\hline Life satisfaction & 351 & 3.7533 & 0.72954 & \multirow{2}{*}{0.609} & \multirow{2}{*}{0.543} & \multirow{2}{*}{0.682} & \multirow{2}{*}{0.000} \\
\hline PERMA & 351 & 3.7287 & 0.37901 & & & & \\
\hline
\end{tabular}


Table 7. Effect of free associations on self-reported well-being components.

\begin{tabular}{|c|c|c|c|c|c|}
\hline & variant & $\mathbf{N}$ & Mean & Std. Deviation & t/sig. (2-tailed) \\
\hline \multirow[t]{2}{*}{ Happiness } & with associations & 220 & 3.9159 & 0.79171 & \\
\hline & without associations & 131 & 4.0352 & 0.66855 & \\
\hline \multirow[t]{2}{*}{ Life satisfaction } & with associations & 220 & 3.6991 & 0.72117 & \\
\hline & without associations & 131 & 3.8394 & 0.73959 & \\
\hline \multirow[t]{2}{*}{ Fl meaning } & with associations & 220 & 3.9233 & 0.69151 & \multirow{2}{*}{$\begin{array}{c}-2.067 \\
0.040\end{array}$} \\
\hline & without associations & 131 & 4.1455 & 0.73836 & \\
\hline \multirow[t]{2}{*}{$\mathrm{Fl}$ accomplishment } & with associations & 220 & 3.4248 & 0.43926 & \multirow{2}{*}{$\begin{array}{c}-2.142 \\
0.034\end{array}$} \\
\hline & without associations & 131 & 3.5728 & 0.48200 & \\
\hline \multirow[t]{2}{*}{ Fl engagement } & with associations & 220 & 3.5128 & 0.43155 & \multirow{2}{*}{$\begin{array}{l}2.270 \\
0.027\end{array}$} \\
\hline & without associations & 131 & 3.6897 & 0.387557 & \\
\hline \multirow[t]{2}{*}{ Fl health } & with associations & 220 & 4.0833 & 0.69903 & \multirow{2}{*}{$\begin{array}{l}2.277 \\
0.024\end{array}$} \\
\hline & without associations & 131 & 3.7949 & 0.63805 & \\
\hline \multirow[t]{2}{*}{ Fl positive emotions } & with associations & 220 & 3.6372 & 0.39480 & \\
\hline & without associations & 131 & 3.6714 & 0.42349 & \\
\hline \multirow[t]{2}{*}{ Fl relations } & with associations & 220 & 3.9499 & 0.58456 & \\
\hline & without associations & 131 & 3.9671 & 0.65745 & \\
\hline \multirow[t]{2}{*}{ Fl happy } & with associations & 220 & 3.9027 & 0.88605 & \\
\hline & without associations & 131 & 3.9718 & 0.79232 & \\
\hline \multirow[t]{2}{*}{ PERMA } & with associations & 220 & 3.3037 & 0.43518 & \multirow{2}{*}{$\begin{array}{l}2.829 \\
0.005\end{array}$} \\
\hline & without associations & 131 & 3.5517 & 0.47570 & \\
\hline
\end{tabular}

Table 8. Differences in PERMA scores.

\begin{tabular}{|c|c|c|c|c|c|c|c|c|}
\hline & \multicolumn{2}{|c|}{$\begin{array}{c}\text { overall } \\
N=30,000\end{array}$} & \multicolumn{2}{|c|}{$\begin{array}{l}\text { Bulgaria } \\
\mathrm{N}=351\end{array}$} & \multirow{2}{*}{$\mathrm{T}$} & \multicolumn{2}{|c|}{$\begin{array}{c}\text { Russia } \\
\mathrm{N}=279\end{array}$} & \multirow{2}{*}{$\mathrm{T}$} \\
\hline & mean & sd & mean & sd & & mean & sd & \\
\hline positive emotion & 6.69 & 1.97 & 6.79 & 0.78 & & 6.65 & 2.03 & \\
\hline engagement & 7.25 & 1.71 & 6.45 & 0.86 & 7.82 & 7.16 & 1.70 & 5.14 \\
\hline relationships & 6.90 & 2.15 & 7.46 & 1.15 & 4.24 & 6.86 & 2.16 & 3.4 \\
\hline meaning & 7.06 & 2.17 & 7.52 & 1.38 & 2.75 & 6.61 & 2.47 & 4.5 \\
\hline accomplishment & 7.21 & 1.78 & 6.48 & 0.95 & 5.32 & 7.03 & 1.86 & 3.64 \\
\hline PERMA (overall wellbeing) & 7.02 & 1.66 & 6.96 & 0.76 & & 6.86 & 1.71 & \\
\hline negative emotion & 4.46 & 2.06 & 7.61 & 1.31 & 24.23 & 4.46 & 2.15 & 8.20 \\
\hline physical health & 6.94 & 2.18 & 6.39 & 0.72 & 2.62 & 7.20 & 2.05 & 5.06 \\
\hline
\end{tabular}




$$
T=\frac{\bar{X}_{1}-\bar{X}_{2}}{\sqrt{\frac{\left[s_{1}^{2}\left(N_{1}-1\right)+s_{2}^{2}\left(N_{2}-1\right)\right] \times\left(1 / N_{1}+1 / N_{2}\right)}{N_{1}+N_{2}-2}}}
$$

There are no significant differences in the overall well-being (PERMA) score, accounted for the Bulgarian sample due to the higher and lower means for its individual components. I have to note that there is no significant difference in positive emotions and general PERMA. Engagement, accomplishment and physical health are lower for the Bulgarian sample. On the contrary, the perceived satisfaction with relationships and experienced meaning are scored higher. Negative emotions are also higher compared to the other subscales. The role of the different components results in keeping the overall balance of flourishing. The different weight of the components can have important practical implications at national level, as well as at individual.

\section{Discussion}

In conclusion, it can be summarized that the results for happiness, life satisfaction and flourishing for this sample are high. This once again replicates the role of the time of administering the instruments, the type of administered instruments and the significance of referring the quantitative results to the framework of meanings. Giving subjective assessment to the experienced well-being, people refer to different intrinsic and extrinsic stimuli and are led by both emotions and rational self-reflection. They experience, but also make evaluations that remain in the context of the objectified external factors.

The single effects of demographic variables are slight and partial. Sex and age have no significant effect. The more is the engagement-work and study at the same time-the happier are people compared to those who neither work, nor study. Married people are happier compared to those, living with others or with partner. People, having income above the average, are happier and more satisfied with life.

The role of the meaning mindset and the different meaning ascribed to the emotional and cognitive components of well-being, are emphasized. While happiness is predicted mostly by intrinsic stimuli, leading for life satisfaction are the extrinsic, followed by intrinsic stimuli. Flourishing, in its turn, combines both the effect of positive emotions, happiness, and relations, and the engagement, accomplishment, and meaning, which to a great extent are linked to the environment and quality of life. Supported by the cross-cultural comparison, the results lead to the conclusion that with view of maintaining optimal balance, we can differentiate the levels and emotional and cognitive predictors of well-being. They can have different measures as feeling both positive and negative affect at the same time. Maintenance of the balance of flourishing, especially in the PERMA model, can be promoted in different domains that can supplement each other and compensate experienced deficits in any domain. This is evident in the general PERMA result, which has no difference for the Bulgarian sample, although the results for some of its components are lower (engagement and ac- 
complishment), which, however, is compensated by the higher scores of other components (meaning and relationships). This namely is the suggested pathway for finding the balance and compensating the negatives, in this case attributed more to the external context. Individuals can learn how to manage and give their assessment higher or lower subjective weight.

The role of associations as leading to some self-reflection and meaning mindset deserves further research. Positive emotions and happiness are not affected by previously generated associations. Concerning the emotional domain people tend to assess their lives in a positive manner. This also refers to the general satisfaction with life. Rationalizing and thinking as self-reflection is mostly related to the key life domains and mostly to the confirmation of own efforts in the environment. This also needs future research because the line of relating self-reflection and associations to universal needs can give raise to a number of conclusions concerning the balance of intrinsic and extrinsic motivation.

In general our expectations are confirmed. The associations related to the measures of well-being have different contents when it comes to happiness, life satisfaction and flourishing. In terms of positive emotions, relations, and happiness, people are led by intrinsic stimuli and therefore their level of happiness and experienced positive emotions are not affected by the environmental and contextual factors. Cognitive assessment of the quality of life represented partially in life satisfaction and flourishing is evident in the generated associations. Evaluation of self-realization cannot be pursued without taking into account the framework and the real environment, hence, people are influenced by the possibilities and restrictions of the direct environment and context and the perceived opportunities. This results in lower scores of self-reported satisfaction, especially after respondents have thought of this. In general, setting the real environment represented in the group without previous associations aside, leads to higher scores for perceived meaning, accomplishment, and engagement. People manage their performance in the different life domains in different way and emotions and evaluations have different weight, depending on the well-being measures.

What is most important is that people spontaneously and/or rationally can manage the balance and maintain their subjective well-being, taking into account the role of the inner stimuli and the importance they attribute to external factors. Conceptualization of well-being is both complex and simple. Its complexity is due to the multidimensional measures comprising both intrinsic and extrinsic predictors. Here, at operational level comes the simplicity-of self-reflection and being mindful of the domains that can be individually managed with view of promoting the optimal functioning. The role of meaning mindset and the different meaning ascribed to the components of well-being, can be implemented in a number of trainings and consultancy programmes.

\section{Limitations}

The responses in the present study are based on self-reported measures, not- 
withstanding the free associations. Data were collected during the summer, which is the period of holidays and joy and this for sure has effect. The findings may not be fully generalizable because the sample taken for the study is based on voluntary convenient sample. In its nature, the study is cross-sectional, thus preventing us to draw causal inferences from the results. The role of associations as illustration of self-reflection deserves further research. Despite the limitations, the results of the study have significant implication. With regard to national framework, they confirm that individuals can subjectively assess life satisfaction, happiness and flourishing in the high end, irrespective of the comparison with other countries. It also demonstrates the role of the instruments administered and the time period of the study, as well as the differences in the time of comparison of cross-cultural data.

\section{Conflict of interest}

The author declares no conflicts of interest regarding the publication of this paper.

\section{References}

Bakalova, B., Bakracheva, M., \& Mizova, B. (2015). Happiness and Life Satisfaction: In Search for Ourselves. Sofia: Colbis. (In Bulgarian)

Bakracheva, M. (2019). Differentiation of Social Roles and Life Domains as Predictor and Promoter of Flourishing. Psych, 10, 1188-1216.

https://doi.org/10.4236/psych.2019.108077

Bakracheva, M. (2009). Identity in 3 Steps. Sofia: Paradigma. (In Bulgarian)

Baltes, P. B., \& Baltes, M. M. (1990). Psychological Perspectives on Successful Aging: The Model of Selective Optimization with Compensation. In P. B. Baltes, \& M. M. Baltes (Eds.), Successful Aging: Perspectives from the Behavioral Sciences (pp. 1-34). New York: Cambridge University Press. https://doi.org/10.1017/CBO9780511665684

Butler, J., \& Kern, M. L. (2016). The PERMA-Profiler: A Brief Multidimensional Measure of Flourishing. International Journal of Wellbeing, 6, 1-48. https://doi.org/10.5502/ijw.v6i3.526

Csikszentmihalyi, M. (1990). Flow: The Psychology of Optimal Experience. New York: Harper and Row.

Diener, E. (1984). Subjective Well-Being. Psychological Bulletin, 95, 542-575. https://doi.org/10.1037/0033-2909.95.3.542

Diener, E., \& Chan, M. (2011). Happy People Live Longer: Subjective Wellbeing Contributes to Health and Longevity. Applied Psychology: Health and Wellbeing, 3, 1-43. https://doi.org/10.1111/j.1758-0854.2010.01045.x

Diener, E., \& Oishi, S. (2000). Money and Happiness. In E. Diener, \& E. M. Suh (Eds.), Culture and Subjective Well-Being (pp. 185-218). Cambridge, MA: MIT Press.

Diener, E., \& Suh, E. M. (1998). Subjective Well-Being and Age: An International Analysis. Annual Review of Gerontology and Geriatrics, 17, 304-324.

Diener, E., Emmons, R. A., Larsen, R. J., \& Griffin, S. (1985). The Satisfaction with Life Scale. Journal of Personality Assessment, 49, 71-75. https://doi.org/10.1207/s15327752jpa4901_13

Diener, E., Wirtz, D., Tov, W., Kim-Prieto, C., Choi, D., Oishi, S., \& Biswas-Diener, R. 
(2009). New Measures of Well-Being. In E. Diener (Ed.), Assessing Well-Being. Social Indicators Research Series (Vol 39, pp. 247-266). Dordrecht: Springer.

https://doi.org/10.1007/978-90-481-2354-4_12

European Social Survey. http://www.europeansocialsurvey.org/

Eurostat. https://ec.europa.eu/eurostat/web/products-eurostat-news/-/DDN-20191107-1

Forgeard, M. J. C., Jayawickreme, E., Kern, M. L., \& Seligman, M. E. P. (2011). Doing the Right Thing: Measuring Well-Being for Public Policy. International Journal of Wellbeing, 1, 79-106. https://doi.org/10.5502/ijw.v1i1.15

Friedman, H. S., \& Kern, M. L. (2014). Personality, Well-Being, and Health. Annual Review of Psychology, 65, 719-742.

https://doi.org/10.1146/annurev-psych-010213-115123

Howell, R., Kern, M. L., \& Lyubomirsky, S. (2007). Health Benefits: Meta-Analytically Determining the Impact of Well-Being on Objective Health Outcomes. Health Psychology Review, 1, 83-136. https://doi.org/10.1080/17437190701492486

Huppert, F. A. (2009). Psychological Well-Being: Evidence Regarding Its Causes and Consequences. Applied Psychology: Health and Well-Being, 1, 137-164. https://doi.org/10.1111/j.1758-0854.2009.01008.x

Huppert, F. A., \& So, T. T. C. (2013). Flourishing across Europe: Application of a New Conceptual Framework for Defining Well-Being. Social Indicators Research, 110, 837-861. https://doi.org/10.1007/s11205-011-9966-7

Huta, V., \& Ryan, R. M. (2010). Pursuing Pleasure or Virtue: The Differential and Overlapping Well-Being Benefits of Hedonic and Eudaimonic Motives. Journal of Happiness Studies: An Interdisciplinary Forum on Subjective Well-Being, 11, 735-762. https://doi.org/10.1007/s10902-009-9171-4

Huyck, M. H. (1993). Middle Age. Academic American Encyclopaedia, 13, 390-391.

Inglehart, R., \& Klingemann, H. D. (2000). Genes, Culture, Democracy, and Happiness. In E. Diener, \& E. Suh (Eds.), Subjective Well-Being Across Cultures (pp. 185-218). Cambridge, MA: MIT Press.

Lachman, M. E. (2004). Development in Midlife. Annual Review of Psychology, 55, 305-331. https://doi.org/10.1146/annurev.psych.55.090902.141521

Lyubomirsky, S., \& Lepper, H. S. (1999). A Measure of Subjective Happiness: Preliminary Reliability and Construct Validation. Social Indicators Research, 46, 137-155. https://doi.org/10.1023/A:1006824100041

Lyubomirsky, S., King, L. A., \& Diener, E. (2005). The Benefits of Frequent Positive Affect: Does Happiness Lead to Success? Psychological Bulletin, 131, 803-855. https://doi.org/10.1037/0033-2909.131.6.803

Maslow, A. H. (1954). Motivation and Personality. New York: Harper \& Row.

Reiss, S., \& Havercamp, S. M. (2005). Motivation in a Developmental Context: A New Method for Studying Self-Actualization. Journal of Humanistic Psychology, 45, 41-53. https://doi.org/10.1177/0022167804269133

Ryan, R. M., Huta, V., \& Deci, E. L. (2008). Living Well: A Self-Determination Theory Perspective on Eudaimonia. Journal of Happiness Studies, 9, 139-170. https://doi.org/10.1007/s10902-006-9023-4

Seligman, M. (2011). Flourish: A New Understanding of Happiness, Well-Being- and How to Achieve Them. Boston, MA: Nicholas Brealey Pub.

Seligman, M. (2012). Flourish: A Visionary New Understanding of Happiness and WellBeing. New York: Atria Books.

Shek, D. T. L. (1996). Mid-Life Crisis in Chinese Men and Women. Journal of Psychology, 
130, 109-119. https://doi.org/10.1080/00223980.1996.9914993

Steger, M. F. (2012). Experiencing Meaning in Life: Optimal Functioning at the Nexus of Spirituality, Psychopathology, and Wellbeing. In P. T. P. Wong (Ed.), The Human Quest for Meaning (2nd ed., pp. 165-184). New York: Routledge.

Stoitsova, T., \& Polio, H. (2004). Manual on Identification of the Figurative Language. Psychological Research, 3, 17-31.

Veenhoven, R. (1984) Conditions of Happiness Reidel. Dordrecht, Netherlands: Springer. https://doi.org/10.1007/978-94-009-6432-7

Veenhoven, R. (1992). Happiness in Nations. RISBO Series: Studies in Socio-Cultural Transformation No. 2. Rotterdam: Erasmus University.

Veenhoven, R. (2000). Freedom and Happiness: A Comparative Study in Forty-Four Nations in the Early 1990s. In E. Diener, \& E. Suh (Eds.), Subjective Well-Being across Cultures (pp. 257-288). Cambridge, MA: MIT Press.

Veenhoven, R. (2009). How Do We Appraise How Happy We Are? In A. Dutt, \& B. Radcliff (Eds.), Happiness, Economics and Politics. Cheltenham, UK: Edward Elgar Publishers.

Veenhoven, R. (2010). Greater Happiness for a Greater Number: Is That Possible and Desirable? Journal of Happiness Studies, 11, 605-629.

https://doi.org/10.1007/s10902-010-9204-z

Veenhoven, R. (2017). Measures of Happiness: Which to Choose? In G. Brulé, \& F. Maggino (Eds.), Metrics of Subjective Well-Being: Limits and Improvements (pp. 65-84). Dordrecht: Springer. https://doi.org/10.1007/978-3-319-61810-4_4

Wong, P. T. P. (2011). Positive Psychology 2.0: Towards a Balanced Interactive Model of the Good Life. Canadian Psychology, 52, 69-81. https://doi.org/10.1037/a0022511

World Happiness Report (2019). https://worldhappiness.report/ed/2019/\#read 